\title{
Commentary on "Hybridity, Globalisation, and Literacy Education in the Context of New York City's Chinatown"
}

\author{
Bettina Fabos \\ Miami University of Ohio
}

By focusing on community and outside literacy practices, the authors attempt to push new literacy studies (NLS) in promising directions by superbly capturing the hybridisation of these Chinese American student-participants in New York's Chinatown. The conclusions are also solid, convincingly advancing the notion that educators should be aware of the importance of building "portfolios of practices and dispositions that correspond and shape one's [students'] interaction with emerging literacy practice" (Albright, Purohit, \& Walsh, 2006, p. 236).

My concerns are with the larger issue of NLS research, which I find increasingly problematic and even inconsequential. By celebrating a range of literacy practices, many grounded in new technologies, our research relentlessly focuses on the "safe" areas of practice and process, and conveniently sidesteps-in a way that often goes unquestioned-the more complex and more political issues of content, quality, and objective: the end results of literacy and learning.

I find that our field is so intent on celebrating new and underprivileged forms of literacy that it is missing a more important argument about qualitative differences: what these new literacies get us. Why are we so afraid to make informed, empirical judgements about various literacy practices? Consistent with NLS research, the authors question the privileged status of book learning and the hierarchical status of school literacy, which is fine. However, in a peer review of their article (and they have ably responded to these points) I suggested that they develop a solid rationale for the celebration of any other literacy practices (be it community-based or grounded in new technologies) beyond the notion that these practices may be

Correspondence should be sent to Bettina Fabos, 5927 Stephenson Road, Oxford, OH 45056, USA. E-mail: fabosb@muohio.edu 
worthwhile in the future. Why does community schooling in a different language/ mother tongue advance literacy and learning? Why does instant messaging (IM)? Why does HTML design?

Indeed, it is far easier to embrace all literacies than to discuss qualifications. I am reminded of the way in which communication studies research has evolved. The field has gone from celebrating oppositional cultural practices simply because they were "oppositional" to more thoughtful consideration of communication and not finding every oppositional practice so precious. Moreover, I have to warn NLS researchers of overcelebrating literacy practices without ever acknowledging content or the political economy in which the content is framed. If the ultimate goal of NLS is to provide "students with the critical competency to discern what is important, to read different kinds of new emerging texts, and to learn to work with them" (Albright et al., 2006, p. XXX), why are we so afraid to consider the possibility that some literacy practices and the content involved in these practices might not be helpful to learners? At what point do we stop celebrating the skills young kids develop by playing Xbox and doing IM and building Web pages and searching for information via search engines (I am including myself here because as a researcher I have participated in this celebration) and, admittedly, as we are well aware, that so many of these practices promote self-gratification, lack of discipline, take up enormous amounts of time, and play into the hegemony of commercial and entertainment culture (which is devoted to selling video games, etc.)? Mind you, when I first wrote this I was at the end of a semester in which I had received the shoddiest work that I had ever seen turned in by college students, and I was burdened by the knowledge that a large number of my students play video games to "relieve their stress" for 2-3 hours each night and do not read books - even those required-and have such a pathetic knowledge base that any attempt at critical literacy is difficult, merely because they do not have enough "hooks" on which to hang information.

Exactly what do online practices such as IM, interactive Xbox gaming, or Web page building have to do with acquiring ideas, information, or a more concrete understanding of our ideological continuum and where ideas are placed on it? How can we talk so blindly about literacy practices without adequately addressing content? Any media is only as good as its content. Are we to continue celebrating video games and Web page building as neutral literacy practices without acknowledging the kinds of games students are playing or the kinds of pages students are building? Is it possible that students are correct to stigmatise certain literacy practices because they are more familiar with the content and, in fact, know better that the video games they play (many of which focus on war or military strategy) are stress relievers and build a certain kind of confidence but that do not add greatly to their knowledge base? Perhaps the authors could consider making distinctions between literacies that lead to physical or mental skills (e.g., hand-eye coordination or problem solving) and literacies that lead to greater knowledge and understanding. 
This is risky territory because, as the authors point out, we do not want to privilege one kind of literacy practice over another. Why? Because we must confront hierarchy issues concerning which practice is better-a task that, in the subtext of this discussion, is political. We must confront the economic imperatives that drive certain literacies, and that is difficult. And we must enter discussions that evaluate content—discussions that are undeniably risky and fraught with ideology.

Literacy studies has thus become a study of practices not of content, a celebration of cultural expression and identity formation that often lacks political, economic, and ideological context (Buschman, 2003, p. 46). However, we must begin to confront issues of content again as they relate to literacy. Which kinds of content, for example, answer important questions, challenge stereotypical views, inspire critical analysis, offer hooks on which to hang other information that can be used for discussion and debate and conflicting opinions (i.e., the seeds of critical literacy)? Which kinds of content are geared toward entertainment, consumer culture, and are created by market forces that push them in certain commercially profitable directions? Just because a new literacy practice, like video games, involves a new technology and is embraced by young people does not automatically mean that its content will, in some ways, benefit greater learning or deeper thinking. Discounting the theory that Doom and Grand Theft Auto make kids more violent, what else, we should ask, are young people learning from these games? On this issue, I appreciate Stephen Johnson's Everything Bad is Good for You (2005) and James Paul Gee's What Video Games Have to Teach Us About Learning and Literacy (2004) and Why Video Games are Good for Your Soul (2005), all of which actually address the question of video game content, with surprising results.

I wonder what is the ultimate goal of NLS research? Is the goal of this research to catalogue and embrace each emerging or undiscovered literacy practice out there so that we can then acknowledge these practices in our teaching? The hybridisation of hybrid subjectivities? The notion that the skills children are learning with video games or IM will, at some point in time, be helpful? Perhaps it will be, but what does that have to do with creating critically literate kids now? I can compare the direction of this research with the overused uses and gratifications research that dominated communication studies journals for decades: Researchers dutifully studied the many, many reasons people watch TV, for example, until they ran out of categories. They subsequently exhausted their research on this question until the next big mass medium (the Internet) came along.

The research trajectory of NLS could be similar. Yes, there are many, many literacy practices that are evolving and merging. It is a complex world out there. But is cataloguing multiple and hybrid literacies the best focus of our research? I suggest that we should instead be asking potentially riskier but more fruitful questions about literacy, ones that have far more to do with education: How do we get students to use language to think through, synthesise, and understand complicated ideas? 
My point is not a reactionary dismissal of NLS but a plea to take our studies to the next level, to evaluate the consequences of these new literacies. Here, I completely agree with the authors' call for 'rethinking, or at least to continually expanding the terms of NLS-in terms of the methodologies used, the questions that are asked, and the conclusions that may be drawn" (Albright et al., 2006, p. 238). If we, as researchers, are not able to critically evaluate the contribution of new literacies toward education, how can we really make an argument about which ones to value? In the world of education, there is a very practical reason to do such research because education budgets often come down to which programmes and ideas are best articulated. These should not be binary arguments of which literacies are good or bad, but they should be nuanced debates about which literacies have the best educational outcomes and in which environments. By outcomes, I do not automatically suggest that we do quantitative number crunching and standardised testing, but that we undertake some means of evaluating which literacies best mesh with the most effective teaching practices.

\section{REFERENCES}

Albright, J., Purohit, K., \& Walsh, J. (2006). Hybridity, globalisation, and literacy education in the context of New York City's Chinatown. Pedagogies: An International Journal, 1, 221-242.

Buschman, J. E. (2003). Dismantling the public sphere: Situating and sustaining librarianship in the age of the new public philosophy. Westport, CT: Greenwood.

Gee, J. P. (2004). What video games have to teach us about learning and literacy. New York: Palgrave Macmillan.

Gee, J. P. (2005). Why video games are good for your soul. Melbourne, Australia: Common Ground. Johnson, S. (2005). Everything bad is good for you. New York: Riverhead Books. 